\title{
Juan de Segobia y los manuscritos de la traducción latina del Corán de Robert de Ketton*
}

\author{
Juan de Segobia and the Manuscripts of the Qur'ān's \\ Latin Translation by Robert of Ketton
}

\author{
Fernando González-Muñoz \\ Universidad de A Coruña \\ ORCID iD: https://orcid.org/0000-0002-1275-1448
}

\begin{abstract}
Resumen
El objetivo de este estudio es demostrar la estrecha relación que media entre dos de los manuscritos que actualmente se conservan de la traducción latina del Corán de Robert de Ketton (1142-1143), y la figura de Juan de Segobia (1390/5-1458), quien desde 1437 había estudiado esta versión del Corán hasta que él mismo, con la colaboración de un alfaquí hispano, elaboró una nueva traducción.

Tras exponer las noticias que Juan de Segobia ofrece sobre los ejemplares del Corán latino que poseyó, se esboza una ordenación general de la tradición manuscrita del Alchoran de Robert de Ketton, que se divide en dos familias, $\alpha$ (la de los códices más antiguos) y $\beta$ (la de los más recientes, derivados de un manuscrito traído en 1437 desde Constantinopla a Basilea por Johannes de Ragusio). La comparación entre la redacción que ofrece un grupo de manuscritos de la familia $\alpha$ (muy en particular, la del códice Paris BNF lat. 3393) con las variantes presentes en los códices de la familia $\beta$ y en la propia edición de Theodor Bibliander (1543) permite concluir que el códice Paris BNF lat. 3669 es una copia de un manuscrito supervisado por Juan de Segobia, donde se ofrecía una redacción del Alchoran de Robert de Ketton revisada a partir de las variantes del códice de Johannes de Ragusio.
\end{abstract}

Palabras clave: Alchoran; Robert de Ketton; Juan de Segobia; tradición manuscrita; Theodor Bibliander.

\begin{abstract}
The aim of this paper is to demonstrate the close relationship between two of the extant manuscripts of the Qur'ān's Latin translation by Robert of Ketton (1142-1143), and the figure of Juan de Segobia (1390/5-1458), who from 1437 had studied this version of the Koran until he himself, with the collaboration of a Spanish alfaqui, produced a new translation.

After exposing the news that Juan de Segobia offers about the copies of the Latin Qur'ān that he possessed, a general arrangement of the manuscript tradition of the Alchoran by Robert of Ketton is outlined. This is divided into two families, $\alpha$ (that of the older codices) and $\beta$ (that of the more recent ones, derived from a manuscript brought from Constantinople to Basel by John of Ragusio in 1437). The comparison between the wording offered by a group of manuscripts of family $\alpha$ (in particular that of the codex Paris BNF lat. 3393) with the variants present in the codices of family $\beta$ and in the edition of Theodor Bibliander itself (1543) allows us to conclude that the codex Paris BNF lat. 3669 is a copy of a manuscript supervised by Juan de Segobia, which offered a revised wording of the Alchoran by Robert of Ketton based on the variants taken from the codex of John of Ragusio.
\end{abstract}

Key words: Alchoran; Robert of Ketton; Juan de Segobia; Manuscript Tradition; Theodor Bibliander.

Cómo citar / Citation: González-Muñoz, Fernando, "Juan de Segobia y los manuscritos de la traducción latina del Corán de Robert de Ketton”, Al-Qantara, 42, 1 (2021), e07. doi: https://doi.org/10.3989/alqantara.2021.007.

Recibido: 07/07/2020; Aceptado: 28/10/2020; Publicado: 02/07/2021

\footnotetext{
* Este estudio se inscribe en el proyecto de investigación: Medieval and Modern Sources for the Study of Transcultural Relations in the Mediterranean: writing and transmission (PGC2018-093472-B-C31) MCIU.
} 
La versión latina del Corán de Robert de Ketton es la pieza principal de un dossier de textos islamológicos cuya traducción al latín encargó Pedro el Venerable con ocasión de su viaje por el norte y noroeste de Hispania, en 1142. Robert de Ketton tradujo el Corán y la llamada Chronica Mendosa et ridicula Sarracenorum. Hermann de Carinthia, el Liber de generatione Mahumeti y la Doctrina Mahumeti; Pedro de Toledo, la Epistola sarraceni y el Rescriptum christiani, esto es, la llamada Risālat al-Kindī. A estas piezas todavía se añadieron dos escritos de Pedro el Venerable: la Summa totius haeresis y la Epistola ad Bernardum. El conjunto de estas obras constituye el llamado Corpus Islamolatinum o Corpus de Cluny, que se transmitió íntegro solo en algunos manuscritos y que, de manera parcial, fue objeto de edición impresa por primera vez en Basilea (1543) por el erudito suizo Theodor Bibliander.

El objetivo de este estudio es demostrar la estrecha relación que media entre dos de los manuscritos que actualmente se conservan de la traducción latina del Corán de Robert de Ketton, finalizada en 1143, y la figura de Juan de Segobia (1390/5-1458), quien desde 1437 había manejado y estudiado esta versión del Corán hasta que él mismo, con la colaboración de un alfaquí hispano, elaboró una nueva traducción, de la que solo conocemos el prólogo y dos fragmentos ${ }^{1}$.

La argumentación que se llevará a cabo requiere, de entrada, dedicar sendos apartados a recoger y ordenar las noticias que Juan de Segobia ofrece sobre los ejemplares del Corán latino que él había manejado, y a exponer las principales agrupaciones que es posible establecer en el conjunto de los manuscritos disponibles.

\section{Los Coranes latinos de Juan de Segobia}

En el prólogo de su propia versión trilingüe del Corán Juan de Segobia hace referencia a los ejemplares de la traducción latina de Robert de Ketton que tuvo en su poder y manejó. El primero fue un códice encadenado, depositado en una

El prólogo, contenido en los mss. Città del Vaticano, BAV Vat. Lat. 2923, ff. 186-196, y Madrid BNE Ms/ 9250, ff. 107-121, fue editado por Cabanelas, Juan de Segovia, pp. 279-302 y por Martínez Gázquez, "El prólogo de Juan de Segobia”, pp. 394-410. Por su parte, los dos fragmentos del texto coránico, que aparecen en los márgenes del ms. Sevi1la, Biblioteca Colombina 7-6-14, fueron editados por Roth and Glei, "Die Spuren der lateinischen Koranübersetzung des Juan de Segovia" y "Eine weitere Spur der lateinischen Koranübersetzung des Juan de Segovia". biblioteca alemana, del que se procuró una copia en $1437^{2}$. En julio de este mismo año recibió en préstamo de Nicolás de Cusa otro ejemplar, que habría conservado en su poder mientras Nicolás permaneció en Constantinopla desempeñando una misión diplomática como representante del papa Eugenio IV ${ }^{3}$. A este códice se refiere también el propio Cusano en el prólogo a su Cribratio Alkorani. Allí introduce dos precisiones importantes: la primera, que lo había hallado en Basilea; la segunda, que contenía, además del Corán, un texto de controversia entre dos nobles árabes, esto es, la traducción de la Risālat al Kind $\bar{l}$, y otros opúsculos, de lo que parece inferirse que el manuscrito en cuestión transmitía la totalidad de los textos del Corpus Islamolati$n \mathrm{~m}^{4}$. Pero todavía Juan de Segobia consiguió hacerse con la reproducción de un tercer ejemplar, que había sido copiado en Constantinopla para Johannes de Ragusio en 1437 y que estaba depositado en la biblioteca del convento dominico de Basilea. A tenor del breve comentario que le dedica: correcte scriptum, parece que la calidad de esta última copia era muy superior a las que previamente había manejado ${ }^{5}$.

2 Et ex tunc multorum percepi relacione, idque ipse agnoui, quod paucissimi Christianorum librum ipsum tenent quodque in paucissimis reperitur librariis, de quarum una, in Germania, librum incathenatum habui, anno XXXVII copiarique feci (Prefacio al Corán trilingüe, ed. Martínez Gázquez, "El prólogo de Juan de Segobia", p. 399, 11. 167-168). Habetur namque liber Alchoran in multis librariis Almanie, et quem ego habui anno XXXVII ex libro cathenato transcribi feci. (Epistola III a Jean Germain, de 18/12/1455, ms. BAV Vat lat. 2923, f. $72 \mathrm{v}$ ).

3 Memorem quippe arbitror dominationem uestram metuendissimam quod, dum Constantinopolim itura foret, multo rogatu meo concessit michi ut copiari facerem librum Alchoran (Epístola a Nicolás de Cusa de 2/12/1454; ms. BAV Vat. lat. 2923 , f. 4v).

4 Translationem per Petrum abbatem Cluniacensem nobis procuratam Basileae habui cum disputatione eorum nobilium Arabum [...]. Erant etiam alia quaedam opuscula [...]. Dimisi librum apud magistrum Iohannem de Segobia et ad Constantinopolim perrexi (Cribratio Alchorani, prologus 2, ed. Sanz Santacruz, Examen del Corán, p. 74).

Quocirca Basileam destinavi pro Alchurano quem uideram in libraria Predicatorum, Constantinopoli scriptum; sed hic conformis erat meo, correcte tamen scriptus. (Prólogo al Corán trilingüe, ed. Martínez Gázquez, "El prólogo de Juan de Segobia", p. 400, 11. 222-224). E igualmente: Habui librum qui Constantinopoli, ut apparet, correcte fuit scriptus dum illic Johannes de Ragusio permansit (Epístola a Nicolás de Cusa de 2-12-1454: ms. Vat Lat. 2923, f. 9r). E Germania habui librum alterum similem meo in Constantinopoli correcte scriptum praedictam aliasque duas super materia translationis continentem epistulas (Prefacio al De mittendo diuini spiritus, ed. Roth, Johannes de Segovia, p. 26, 11. 294-296). 
Como es bien sabido, este códice del convento de Basilea es el mismo que, alrededor de un siglo después, colacionó Theodor Bibliander para elaborar la edición de la versión latina del Corán. De hecho, en la segunda edición de 1550, al final del texto coránico, Bibliander reprodujo el colofón de ese manuscrito, copiado en Constantinopla en enero de 1437 por Clemens Polonus de Vislicia a instancias de Johannes de Ragusio.

Un problema derivado de las constataciones anteriores es determinar el origen del manuscrito al que se refiere el Cusano en el prólogo de la Cribratio. Nicolás declara haberlo hallado en Basilea, pero esto no aclara si estaba depositado en una biblioteca local o si había sido traído a la ciudad por alguno de los participantes en el concilio. Otra cuestión dudosa es si debe identificarse o no con el códice 108 de la Hospitalbibliothek de Bernkastel-Kues. Una dificultad para la identificación estriba en el hecho de que el ejemplar de Kues no presenta la Epistula sarraceni, y que el Rescriptum christiani, al igual que la Epistola ad Bernardum, fueron copiados por una mano diferente a la que transcribió las restantes piezas.

\section{Los manuscritos del Corán latino de Robert de Ketton: principales agrupaciones}

Fue M. ${ }^{a}$ Thérèse D'Alverny ${ }^{6}$ la primera estudiosa que efectuó el censo de los códices del Corpus Islamolatinum que han llegado hasta nosotros, un total de veinticinco, a los que todavía habría que sumar uno más preservado en una colección particular, del que no contamos con información alguna, a excepción de que fue copiado en Zurich en octubre de $1542^{7}$.

En el presente estudio no se tomará en consideración el manuscrito El Escorial \& IV.8. ff 1-217 (s. XVII) por ser una copia del texto coránico hecha a partir de la edición de Bibliander por el dominico Germán de Sile$\mathrm{sia}^{8}$. De los veinticuatro códices restantes, el de Paris, BNF Arsenal 1162 (en adelante $A$ ), de mediados del siglo XII, es, como se admite desde los estudios de D'Alverny, el primer ensayo de constitución del Corpus. Se trata de un ejemplar posiblemente elaborado en el pro-

\footnotetext{
6 D’Alverny, "Deux traductions latines", pp. 77-78; D’Alverny, “Quelques manuscrits", pp. 202-206.

7 Bobzin, Der Koran, p. 224.

8 D'Alverny, "Quelques manuscripts de la Collectio Toletana", p. 217.
}

pio scriptorium de Cluny, donde uno o varios escribas copiaron con una caligrafía muy clara y esmerada las traducciones redactadas en Hispania. Hecho esto, los textos fueron revisados, corregidos en no pocos lugares y profusamente anotados. El autor de estas intervenciones fue probablemente Pedro de Poitiers, secretario de Pedro el Venerable y responsable de la coordinación editorial del corpus.

Concluido el proceso de revisión y anotación, en el propio scriptorium de Cluny debió de efectuarse una copia en limpio de este manuscrito «de trabajo». La nueva presentación de la colección incorporaba varias novedades: a) la reordenación de alguna de las piezas, en particular, el desplazamiento al final del volumen de la Epistola ad Bernardum, que en el manuscrito del Arsenal se encontraba al principio, únicamente precedida de la Summa totius haeresis, b) la supresión de un buen número de las anotaciones interlineales más breves, que ya no aparecerán en ninguno de los manuscritos posteriores ${ }^{9}$, c) la supresión de algunos sectores de texto condenados mediante tachadura, que, igualmente, ya no se leen en ningún otro manuscrito ${ }^{10}, \mathrm{y} d$ ) la consignación de la mayor parte de las correcciones supralineales a las lecturas originales del texto ${ }^{11}$. Es este ejemplar revisado y enmendado el que debe ser considerado el arquetipo de los restantes códices.

De la colación del texto coránico en los veintitrés manuscritos restantes puede inferirse que existen dos grandes familias, que identificaré con las siglas $\alpha y \beta$.

A la familia $\alpha$ pertenecen todos los testigos de los siglos XIII, XIV y XV, a excepción de los tres siguientes: Paris BNF lat. 3392 (s.

$9 \quad$ Así, por ejemplo, en el manuscrito de la Biblioteca del Arsenal la sura 5 presenta un total de 109 anotaciones, entre marginales y supralineales. De estas, 29 no se encuentran en ningún otro de los restantes códices.

10 A manera de ejemplo, en el f. 97ra del manuscrito de la Biblioteca del Arsenal, a la altura del pasaje de la azora 35, correspondiente a Qur'ān 26:198, se lee: si librum autem hunc cuilibet algemi traderemus ad legendum. La lectura tachada algemi, ausente en los restantes manuscritos, tiene plena correspondencia con la redacción árabe (Qur'ān 26:198): 'si lo hubiéramos revelado a uno de los no árabes' (= al-’A'ŷamīna).

11 A manera de ejemplo: genitalia por uirilia en el folio 86vb del manuscrito de la Biblioteca del Arsenal, perteneciente a la azora 29 (= Qur'ān 20:121): Unde cibatis illis, menbra aritia ( $\rightarrow$ genitalia) patuerunt, quae de paradisi foliis sumptis tegere nitebantur. Genitalia, por supuesto, es la lectura unánime de todos los demás códices. 
$\mathrm{XIV})^{12}\left(P^{3}\right)$, Città del Vaticano, BAV Vat. Lat. 4071 (s. XV) $\left(V^{I}\right)$ y Paris BNF lat. 3669 (s. $\mathrm{XV})\left(P^{7}\right)$. Son en total los catorce que se relacionan a continuación, por orden cronológico aproximado:

\author{
$P^{2}$ : Paris, BNF lat. 3391, ff. 17-106v (s. XIII), per- \\ gamino. \\ $P^{6}$ : Paris, BNF lat. 3668, ff. 28r-150v (s. XIII), \\ pergamino. \\ $O^{I}$ : Oxford, Corpus Christi College 184, ff. 50- \\ 272 (s. XIII), pergamino. \\ $O^{2}$ : Oxford, Bodleian Library, Selden Supra 31, ff. \\ 33r-204v (s. XIII), pergamino. \\ $P^{l:}$ Paris, BNF lat. 3390, ff. ff. 28r-152v (s. XIII), \\ pergamino. \\ $P^{11}$ : Paris, BNF lat. 6064, ff. ff. 14v-82v (s. XIII / \\ XIV), pergamino. \\ $V^{2}$ : Città del Vaticano, BAV Vat. Lat. 4072, ff. \\ 24r-184r (s. XIV), papel.
}

$T$ : Troyes, Médiathèque du Grand Troyes Ms. 1235, ff. 34r-191r (s. XIV), pergamino.

$P^{13}$ : Paris, BNF lat. 14503, ff. 264v.-352r. (s. XIV), pergamino.

$O^{3}$ : Oxford, Merton College 313, ff. 29r-158v (s. XIV), pergamino; concluye en la sura 78.

$M^{i}$ : Biblioteca Ambrosiana C. 201, ff. 29v-164v. (s. XV), papel.

$B$ : Bernkastel-Kues, Bibliothek des St. Nikolaus-Hospitals, 108, ff. 30v-107r (s. XV), papel.

$P^{4}$ : Paris, BNF lat. 3393, ff. 26v-153v (s. XV), papel.

$S^{p}$ : San Petersburgo, Publichnaya Biblioteka Lar.

Q. I. 345, ff. 38v-212v (s. XV / XVI), papel.

Todos estos códices comparten un amplio número de variantes disjuntivas con respecto al ms. de la biblioteca del Arsenal $(A)$ y a los representantes de la familia $\beta$. Dado el elevado número de ejemplos, me limitaré a exponer unos pocos suficientemente ilustrativos ${ }^{13}$.

\section{Familia $\alpha$}

dum omnipotens placere

summa corona condecorabitur

ab ipso dispositos

obsequio Deique dilectione

ad ignem omnis ingressus tendat

tertio uero relicte sprete

dotis sue dimidium

molestiam inde agat

uirtutum Dei dilectionem

inter Deum uirosque

omissa

germane collactanee

omissa

sed nulla interfecerunt

terram sanctam scilicet

tu minime sustineas

supplementum

misericorditer

omissa

omissa

licet eorum hoc ignorent

quos uoluerit reuocare

pro amore uestro

omissa

nisi se malos esse uellent

omissa

susciperent
12 Este manuscrito presenta un conjunto de variantes propias de la familia $\alpha$, pero en ocasiones coincide $\operatorname{con} \beta$ o conserva lecturas solo atestiguadas en el manuscrito de la Biblioteca del Arsenal. Desafortunadamente, el texto coránico se detiene a la altura de la sura 63 , de manera que no es posible saber si, en su estado original, transmitía las epístolas del musulmán y el cristiano o la Epístola a Bernardo.
13 Todas las referencias a los números de suras y aleyas se corresponden con la edición de Lappin, Alchoran Latinus. Vol. III. 
28:210: aequor

56:15: dator

60:19-20: ego quidem hominis conditor 69:21-22: ueraces... uenientes 74:12: uias Dei rectas docere 81:5: placitumque dilatabitur 83: 21: totum legere non potes 84: 5: tuasque uestes emundare 97:1-2: nomen Dei sublimis

Dentro de esta amplia familia es posible establecer agrupaciones particulares conforme a distintos criterios. D'Alverny, por ejemplo, propuso diferenciar aquellos manuscritos que conservaban el corpus completo, incluidas las cartas del musulmán y el cristiano y la epístola a Bernardo de Claraval, de aquellos otros que habían perdido esas tres piezas ${ }^{14}$. Tendríamos, de esta suerte, una rama $\alpha^{1}$ integrada por los manuscritos completos (esto es: $O^{1}, P^{11}, V^{2}, M^{i}, B, P^{4} \mathrm{y}$, con más reservas, $\left.P^{13}\right)^{15}$, y otra $\alpha^{2}$ exenta de las tres epístolas, representada por los códices $O^{2}, P^{2}, P^{6}, P^{1}, T^{r}$, $O^{3}, S^{p}$. A su vez, en ambas ramas se detectan conexiones particulares entre cada uno de los manuscritos del siglo XIII y los más tardíos, de los siglos XIV y XV. No voy a ocuparme ahora de esta cuestión, si bien, más adelante examinaré uno de los subgrupos de la rama $\alpha^{l}$.

Por su parte, la familia $\beta$ comprende siete manuscritos relativamente tardíos; son los siguientes:

$V^{l}$ : Città del Vaticano, BAV, Vat. Lat. 4071, ff. 23r-127 (s. XV), papel.

$P^{8}$ : Paris, BNF lat. 3670, ff. 1r-196v (s. XVI, ann. 1515/6), papel.

14 D’Alverny, "Deux traductions latines", pp. 97 y 111112.

15 Como señala D'Alverny ("Deux traductions latines", pp. 110-111), el manuscrito $P^{13}$ presenta los tratados en un orden poco habitual, disociando la Epistola ad Bernardum y las epístolas del sarraceno y el cristiano del resto de las piezas, como si hubiesen sido copiadas a partir de un modelo diferente. Si así fuese, cabría la posibilidad de que el texto coránico hubiese sido copiado de un manuscrito en el que faltasen las cartas del musulmán y el cristiano. mare

largitor

hodie quidem hominis conditor

omissa

uias Dei directas docere

placitum et uindicta Dei differetur

totum alchoran legere non potes

omissa

nomen sublimis

$M^{a}$ : Mantova, Biblioteca Comunale Teresiana cod. 65 (A.III.1), ff. 81r-419r (s. XVI), papel.

$T^{0}$ : Torino, Biblioteca Nazionale H.II.33 (1213), ff. 7r-205v (s. XVI), papel.

$D$ : Dresden, Sachsische Landesbibliothek, Mscr. Dresd A. 120b, ff. 73-205 (s. XVI), papel.

$W$ : Österreichische Nationalbibliothek $\operatorname{cod} 4815$, ff. 4v-167r (s. XVI), papel.

$K$ : Karlsruhe, Badische Landesbibliothek Aug. Pap. 112, ff. 3v-186r (s. XVI), papel.

Estos siete códices tienen en común el hecho de transponer un extenso sector de texto: et obstrepentibus ... dimittentes cum: (17:244... 17:385) desde la primera parte de la sura 17 a la segunda parte (que en la numeración de Bibliander es ya la 18), justo a continuación de: non distulit dicens: ego (18:103-4). Comparten, además, un conjunto de variantes disjuntivas con respecto al manuscrito $A$ y a todos los representantes de la familia $\alpha$, pero a la vez, como hemos visto, coinciden con $A$ frente a aquellas variantes características de la familia $\alpha$. Para no multiplicar los ejemplos, expondré unos pocos suficientemente representativos de lecturas divergentes con $A$ y $\alpha$ 
A $\alpha$

s. 2:149-50: preferentes

s. 2bis:78: litem fortiter sustentare

s. 3:6: patrie pernitiem gentique flagitium

3:6-7: fructibusque terre pestem inducer

3:14: singuli semper expectent

4:23: de Deo contentionem

4:32: cibumque tuum et uinum

4:53: grano loco fertili seminato

5:7: quedam uero quasi contraria

5:46: tutoris atque uindicis expertes

5:53: pauperes subleuans

5:58: secreta cordis

10:121: dilectores ${ }^{16}$ hominum

20:75: uestra loca pulcra uideri fecimus

22:22: pecora et se spatiatum

31:124-5: nos saluamus semper credentes

36: 66: sicque Moysen omnesque suos...

38:85: Hemen autem precepit

56: 60-1: ad auditum Alchoran

59:40: actus uestros omnes dinoscens

68:11-12: sexaginta pauperes (om. $\left.M^{i} B P^{4}\right)$

71:12: Vobisque bonum nuntium affero

74:21: Nostrisque contradicentes

76: 19-20: peccamina dimissurus

76:34: nostram animam insufflauimus

77: 41: eius nos tutele supponimus

79:7-8: quorum si quisquam superstes...

79:32-33: a me diuinitus proferret

80:30: dedecus diei

91:4-5: marium

Es interesante constatar en este punto que la mayor parte de las variantes características de la familia $\beta$ coinciden con las lecciones de la edición de Bibliander. Esto mismo ocurre con otros textos del Corpus. Por ejemplo, el incipit de la Summa totius heresis en la edición de Bibliander: Incipit quaedam summula breuis contra haereses et sectam diabolicae fraudis Saracenorum siue Ismahelitarum es el mismo que el de los manuscritos $V^{1}, M^{a} D$ y $T^{b}$ (todos de la familia $\beta)^{20}$ y también del códice Paris BNF lat. $3669\left(P^{7}\right)$ que, como veremos, guarda relación con este grupo.

16 En $A$ directores es la lectura original, pero una anotación supralineal: $u e l-l e c$ - propone conjeturalmente la variante dilectores. Esta última es la que seleccionan los códices de la familia $\alpha$.

17 Es una glosa incorporada al texto. En $A$ aparece como anotación supralineal (f. 100ra).

18 Malos homines en $D T^{b}$; malos en $P^{7} V^{1} P^{8} M^{a} W K$ $B i b l$. Es una glosa incorporada al texto (así en el ms. $A$, f. 120v).

19 Vestrisque en $W K B i b l$.

20 Recuérdese que los otros tres códices de esta familia $\left(P^{8}, W\right.$ y $\left.K\right)$ no contienen la Summa totius heresis.

\author{
$\beta$ Bibl. \\ presentes (parantes: Bibl.) \\ litem sustentare \\ pernitiem gentique flagitium \\ fructibusque pestem inducere \\ singuli simpliciter expectant \\ de Deo disputationem \\ cibumque tuum \\ grano loco sterili seminato \\ quedam uero contraria \\ tortoris atque uindicis expertes \\ pauperes eleuans \\ secreta Deus \\ directores uel dilectores hominum \\ omissa \\ omissa \\ nos saluamus singulariter credentes \\ sicque credentes Moysen omnesque suos... \\ Hemen autem illi artifici ${ }^{17}$ precepit \\ ad auditum Alchoran malos homines ${ }^{18}$ \\ actus uestros dinoscens \\ quadraginta pauperes \\ uobisque nuntium affero \\ $\underline{\text { nostrisque }}^{19}$ preceptis contradicentes \\ peccata dimissurus \\ animam insufflauimus \\ eius nos tutele supposuimus \\ quare si quisquam superstes \\ a me profertur \\ dedecus fidei \\ omissum
}

Sabemos que Bibliander cotejó tres manuscritos del Corán de Ketton y un códice árabe ${ }^{21}$. Entre los primeros estaba el ejemplar copiado en Constantinopla para Johannes de Ragusio en 1437 y custodiado en el convento dominico de Basilea. El hecho de que Bibliander consignase el colofón del mismo en la segunda edición de 1550 hace pensar que fue su modelo principal ${ }^{22}$.

De todo ello puede deducirse, con un grado razonable de certeza, que todos los manuscritos de la familia $\beta$ remontan, a través de diferentes intermediarios, al manuscrito traído a Basilea

21 En el epígrafe a la lista de variantes que Bibliander adjuntó al texto se lee: Annotationes uariae lectionis diuersorum quatuor exemplarium quibus in describendo conferendoque sumus usi (Bibliander, Machumetis Saracenorum principis, p. 230).

22 Per manus Clementis Poloni de Vislicia, ano Domini millesimo ccccxxxvii, mensis Ianuarii ultima, in Constantinopoli, et ad instantiam magni Ioannis de Ragusio, ordinis praedicatorum, tunc in Constantinopoli degentis. (Bibliander ed. Machumetis Saracenorum principis, ed. 1550, p. 188). Véase sobre esto: D'Alverny, "Deux traductions latines", pp. 103-105; Segesvary, L'Islam et la Réforme, pp. 166-168; Bobzin, Der Koran, pp. 222-224; Langeloh, Der Islam auf dem Konzil von Basel, pp. 22-24. 
por Johannes de Ragusio. De hecho, los tres códices latinos que manejó Bibliander presentaban la misma trasposición de texto en la azora 17 característica de la familia $\beta$, según advierte el editor en la siguiente nota:

Transposita fuere haec in tribus quibus usi sumus exemplaribus, ut signa indicant infra paulo (Bibliander ed. Machumetis Saracenorum principis. p. 56, 1.18 ad marg.: * et obstrepentibus) $)^{23}$.

\section{El grupo $M^{i} B P^{4}$ de la familia $\alpha$}

Una vez diferenciadas estas dos ramas principales, es hora de describir con mayor detalle uno de los grupos particulares de manuscritos que integran la familia $\alpha$. Me refiero a los códices Milano, Biblioteca Ambrosiana C. 201 $\left(M^{i}\right)$, Bernkastel-Kues, Hospitalbiliothek 108 $(B)$, y Paris BNF lat. $3393\left(P^{4}\right)$, todos del siglo $X V$. El parentesco entre estos tres manuscitos se constata por diferentes vías: de un lado, los tres ofrecen los mismos defectos de compaginación, que han dado a lugar a la siguiente ordenación de las suras:
Clareuallis de impia secta Machometi, filii dyaboli et primogeniti Sathane. Además, el cotejo del texto coránico arroja un altísimo número de variantes compartidas y exclusivas de este grupo.

También se dan algunas divergencias significativas entre los tres códices. $M^{i}$ conserva los epígrafes y la numeración originales de las suras, que en $P^{4}$ y en $B$ no se transcribieron ${ }^{24}$. Además, como ya se ha señalado, mientras que $M^{i}$ y $P^{4}$ contienen el corpus completo, en $B$ falta la Epistola sarraceni, y tanto el Rescriptum christiani como la Epistola ad Bernardum, transcritos por una mano diferente a la que copió los restantes textos, parecen un añadido a la configuración inicial del códice. Por último, los tres manuscritos presentan anotaciones marginales, especialmente abundantes en $B$ y en $P^{4}$, muy escasas en $M^{i}$. Ahora bien, ninguna de estas se identifica con las glosas primitivas, sino que constituyen nuevas aportaciones de poseedores o lectores contemporáneos a los códices mismos.

Aunque los tres códices tienen un parentesco evidente, hay razones para suponer que no existen relaciones de dependencia directa entre unos y otros, sino más bien un modelo común:

\begin{tabular}{|c|c|c|}
\hline Paris & Kues & Milano \\
\hline $1-77$ & $1-77$ & $1-77$ \\
\hline 78 (1-31: verum...mathema-) & 78 (1-31: verum...mathema-) & 78 (1-31: verum...mathema-) \\
\hline 81 (12-32 : diligatue... existit) & 81 (12-32 : diligatue... existit) & 81 (12-32 : diligatue...existit) \\
\hline $82-85$ & $82-85$ & $82-85$ \\
\hline 86 (1-23: per angelos...pote-) & 86 (1-23: per angelos...pote-) & 86 (1-23: per angelos...pote-) \\
\hline 78 (31-37 : -tico... commendans) & 78 (31-37 : -tico... commendans) & 78 (31-37: -tico... commendans) \\
\hline $79-80$ & $79-80$ & $79-80$ \\
\hline 81 (1-12: Michi...odiat) & 81 (1-12: Michi...odiat) & 81 (1-12: Michi...odiat) \\
\hline 95 (9-10: artium...dimitte) & 95 (9-10: artium...dimitte) & 95 (9-10: artium...dimitte) \\
\hline $96-101$ & 96-101 & $96-101$ \\
\hline 102 (1: per ...nequaquam) & 102 (1: per ...nequaquam) & 102 (1: per ...nequaquam) \\
\hline 86 (23-31: -decipiatis...reprobis) & 86 (23-31: -decipistis...reprobis) & 86 (23-31: -decipistis...reprobis) \\
\hline $87-94$ & $87-94$ & $87-94$ \\
\hline 95 (1-8: per celum...increduli) & 95 (1-8: per celum...increduli) & 95 (1-8: per celum...increduli) \\
\hline 102 (3-8: repertum... partire) & 102 (3-8: repertum... partire) & 102 (3-8: repertum... partire) \\
\hline $103-123$ & $103-123$ & $103-123$ \\
\hline
\end{tabular}

Otros rasgos comunes a los tres y exclusivos de ellos son el epígrafe que figura al inicio del corpus: Incipit lex siue doctrina Machumeti multa mirabilia continens, y el explicit a la Epistola a Bernardo: explicit epistula domini Petri abbatis Cluniacensis ad dominum Bernardum abbatem

23 A pesar de que los tres manuscritos latinos presentaban esta transposición, en la edición de Bibliander el orden es el correcto. a) $B$ no puede ser el modelo de $M^{i} y P^{4}$, pues, como se ha visto, no contiene la carta del musulmán y omite no solo los epígrafes de las suras (como $P^{4}$ ) sino también los tituli de las diferentes piezas del corpus, que en $P^{4}$ y $M^{i}$ sí se conservan. En el texto del Corán $B$ presenta otras

24 En $B$ se han omitido por completo los números de las suras. En $P^{4}$, en cambio, se han consignado al margen a partir

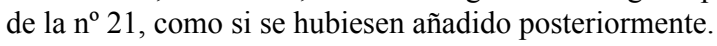


omisiones particulares, por ejemplo: en la sura 29:39-41: utinam ... inquit, en la sura 32:122-3: atque mortificat nec non et resuscitat, en la sura 83:18-19: ante duarum tertiarum, quandoque medietatis nonnunquam etc.

b) $M^{i}$ tampoco puede ser el modelo de $P^{4} \mathrm{y}$ $B$, pues presenta omisiones parciales de las que aquellos están exentos, así, por ejemplo, en la sura 83: 22-24: tuo lectionibus insistis... omnes itaque pro posse; o en la sura 99:9: me diligit. Victum autem tenuem.

c) Por último, el manuscrito $P^{4}$ también ofrece en muchos puntos omisiones y faltas de copia específicas, lo que demuestra que no puede ser el modelo de $B$ ni $M^{i}$. Así, en la sura 34:4 $P^{4}$ arroja la lectura septem ictus suscipiat, frente al resto de los manuscritos: centum ictus suscipiat. Asimismo, en 33:12-13, $P^{4}$ presenta maledicamur frente a los restantes códices: dicant: ' $m a$ ledicamur si mentimur'. En la sura 41: 37-38: $P^{4}$ omite: Tu itaque, puer mi, orationes funde iusque notum. Recuérdese, además, que, a diferencia de $M^{i}, P^{4}$ omite los epígrafes de las suras.

Las observaciones relativas a la morfología de los códices y de los textos que transmiten deben contrastarse con los escasos, pero importantes, datos que poseemos sobre la historia de los manuscritos mismos. El códice $B$ perteneció a Nicolás de Cusa y, de hecho, las anotaciones marginales que contiene son autógrafas ${ }^{25}$. Si su modelo fue el ejemplar mencionado en el prólogo a la Cribratio, el copista decidió prescindir de la Epistula Sarraceni, que sí figura en $P^{4}$ y $M i$. Por lo demás, si bien el Cusano conoció, en primera instancia, el texto coránico a través de una copia especialmente mala, hacia 1462 manejaría un ejemplar mucho mejor perteneciente a la familia $\beta$, el manuscrito BAV Vat. Lat. 4071 $\left(V^{I}\right)$, que presenta un rico aparato de glosas autógrafas del propio Nicolás de Cusa ${ }^{26}$.

Por su parte, el códice $M^{i}$ perteneció a Francesco Pizolpasso (ca. 1375-1443), participante en el concilio de Basilea desde 1432, donde estableció estrechas relaciones con Nicolás de Cusa, Eneas Silvio Piccolomini y Juan de Cervantes, y arzobispo de Milán entre 1435 y $1443^{27}$. Fue seguramente en Basilea donde halló el modelo

\footnotetext{
25 Biechler, “Three Manuscripts on Islam”, pp. 91-100.

26 Martínez Gázquez, “A New Set of Glosses”, pp. 295 309.

27 Ferrari, "Un bibliotecario milanese del Quattrocento", pp. 175-270.
}

de su ejemplar, que podría fecharse, por tanto, entre 1432 y $1437^{28}$.

Sobre el códice $P^{4}$ no tenemos apenas datos. En el catálogo de la BNF aparece adscrito a fines del siglo XIV, pero me parece más probable datarlo en época próxima al de sus compañeros de grupo, esto es, en la primera mitad del siglo $\mathrm{XV}^{29}$. Su particularidad más reseñable es el rico aparato de anotaciones marginales que glosan los diferentes textos. A diferencia de las primitivas, estas notas tienen escaso interés polemístico o hermenéutico, puesto que su objetivo principal es sintetizar, párrafo por párrafo, los contenidos principales de cada sura. En todo caso, el anotador es un lector atento, que procura contrastar los pasajes que lee con fuentes complementarias $^{30}$.

En conclusión, Nicolás de Cusa había hallado en Basilea una versión integral del Corpus Islamolatinum, de la que hizo una copia parcial $(B)$. Probablemente ese mismo códice de Basilea habría sido copiado íntegramente para Francesco Pizolpasso durante los años en que este participó en el concilio $\left(M^{i}\right)$. Por su parte, el manuscrito $P^{4}$ está estrechamente relacionado con $B$ y $M^{i}$, pero no es el modelo ni el descendiente directo de ninguno de los dos. Resulta tentador identificarlo con algún ejemplar derivado de los dos primeros manuscritos manejados por Juan de Segobia, esto es, el librum incathenatum depositado en una biblioteca alemana y el ejemplar que en 1437 le prestó Nicolás de Cusa. Si así fuese, las anotaciones a $P^{4}$ podrían pertenecer al propio Juan de Segobia y ser interpretadas como exponente de la minuciosa labor de lectura y análisis del Alchoran que aquel llevó a cabo desde 1437. Algunas consideraciones adicionales refuerzan esta hipótesis: la marca de agua del papel es semejante a la de otros manuscritos procedentes del scriptorium de Aiton. Además, como se examinará en el apartado siguiente, hay

28 Sobre este manuscrito, véase Langeloh, Der Islam auf dem Konzil von Basel, pp. 25-26.

29 La marca de agua del papel pertenece a una tipología próxima a la de los manuscritos del siglo XV del área centroeuropea: cabeza de toro, con ojos, hocico y orejas, coronada por un signo estrellado (Briquet, Les filigranes, $n^{\circ} 14226$ ). De hecho, resulta semejante a la del ms. Vat. Lat. 2923, un códice de Juan de Segobia procedente del priorato de Aiton. Sobre la descripción de este último, véase: Scotto, "Juan de Segovia's Last Manuscript”, p. 63.

30 A manera de ejemplo, nótese la anotación a una referencia del Rescriptum christiani relativo a dos pasajes coránicos sobre el supuesto adulterio de ' $\overline{\mathrm{A}}$ 'iša: non reperio ista uerba in Alchorano meo (f. 167v). 
un buen número de variantes compartidas por $P^{4}$ y otro de los códices del Corpus Islamolatinum indudablemente relacionado con Juan de Segobia. Ahora bien, las notas marginales a $P^{4}$ no parecen autógrafos de Juan de Segobia ${ }^{31}$ y, por otra parte, resulta extraño que si Juan de Segobia dispusiese desde 1437 de una copia integral del Corpus Islamolatinum no hubiese introducido en su epistolario ni en sus escritos de controversia contra el islam ninguna cita ni referencia expresa a textos de tanto interés como el Rescriptum Christiani ${ }^{32}$. Hay, pues, razones para sospechar que, si bien los modelos ofrecían el corpus íntegro, las copias que Juan de Segobia encargó fueron parciales, limitadas al texto coránico.

\section{El manuscrito Paris BNF lat. 3669}

Me ocuparé ahora de otro de los ejemplares del Corpus Islamolatinum al que todavía no me he referido. Se trata del códice Paris BNF lat. $3669\left(P^{7}\right)$, integrado por 225 folios en papel y datable en la segunda mitad del siglo $\mathrm{XV}^{33}$. Su contenido es el siguiente:

\section{ff. 1-3r: blancos.}

f. 3v: In Alchoran Machometi: Martinus prepositus Lausanensis: poema contra el Corán en dieciséis hexámetros compuesto por Martin le Franc (ca. 1408-1461), preboste de Lausanne desde 1443 y secretario apostólico del antipapa Félix V (1439-

31 Agradezco, a este respecto, los comentarios de José Martínez Gázquez y Davide Scotto, buenos conocedores de la caligrafía de Juan de Segobia, quienes me han transmitido su impresión de que esas notas no son de la mano de aquel.

32 Juan de Segobia cita un par de veces el Resciptum Christiani (De gladio 8:161-162; 32:287-315), pero a partir de los excerpta de Vincent de Beauvais. Tampoco parece haber prestado mucha atención a las traducciones de Hermann de Carinthia o a la Chronica Mendosa, si es que las llegó a conocer. Sí parece haber leído la Summa totius heresis, pero solo en el manuscrito de Johannes de Ragusio: véase De gladio, praef. 292-297: Prius autem quam hanc epistulam uidissem pro magna parte tractatum compleueram, sed cum liber Alchoran iam a xvii annis penes me existens incorrectus esset, ex Germania habui librum alterum similem meo in Constantinopoli correcte scriptum praedictam aliasque duas super materia translationis continentem epistulas, propter quod excerpta, tamquam correcta sint, inserui... De lo que se infiere que el códice de Johannes de Ragusio contenía, además de la Summa totius heresis (hanc epistulam), la epistola ad Bernardum y el prefacio de Robert de Ketton al Alchoran (aliasque duas super materia translationis).

33 D'Alverny, "Deux traductions", p. 112 y Burman, Reading the Qur'an, p. 98 y n. 69.
1449). En el margen inferior de este folio aparece la firma del poseedor del códice: De comitibus.

ff. 4r-8r: Summula breuis contra hereses et sectam dyabolici fraudis Sarracenorum siue Ysmahelitarum: texto de Pedro el Venerable que, en la mayor parte de los manuscritos que lo transmiten, encabeza el Corpus Islamolatinum.

ff. 8v-9v: Epistola domini Petri abbatis ad dominum Bernardum Clareuallis abbatem de translatione sua qua fecit transferri ex arabico in latinum sectam siue heresim sarracenorum: epístola de Pedro el Venerable a Bernardo de Claraval, que acompañaba el envío a éste de la Epistola Sarraceni y el Rescriptum Christiani.

ff. 10r-v: Prologus Roberti translatoris uiri eruditi et scolastici ad dominum Petrum Cluniacensem. Prólogo del traductor Robert de Ketton a la Chronica mendosa et ridicula sarracenorum.

ff. 11r-v: blanco

ff. 12r-13r: Prefatio Roberti translatoris ad dominum Petrum abbatem Cluniacensem in libro legis sarracenorum quem Alchoran uocant, id est, collectionem preceptorum Mahumeti pseudo propheta per angelum Gabrielem, quae de celo sibi missa confixit. Prefacio de Robert de Ketton a la traducción del Corán.

ff. 13r-212v: Lex sarracenorum, quam Alchoran uocant, id est, collectionem preceptorum. Traducción de Robert de Ketton del Corán. Texto íntegro, dividido en 123 suras, y con algunas anotaciones marginales de varias manos, diferentes, en todo caso, de las glosas primitivas presentes en los manuscritos más antiguos del Corpus ${ }^{34}$.

ff. 213r-220v: Secuntur ex plurimis in ea contentis pauci errores legis Mahumeti excerpti de libro legis ipsius Alchoran nominati. Se trata del texto de Juan de Segobia conocido comúnmente con el nombre de Errores legis Mahumeti ${ }^{35}$.

ff. $221 \mathrm{r}-225 \mathrm{v}$ : blancos. En el margen superior del folio 225v figura un ex libris del siglo XVI: Est mei Stephani de Comitibus ill. doc. Se trata, sin duda, del mismo personaje que firma en el folio $3 \mathrm{v}$.

La configuración de este manuscrito es singular, pues es el único ejemplar del Corpus Islamolatinum que presenta una selección de textos integrada por las dos aportaciones del abad de Cluny, los dos prefacios de Robert de Ketton y la traducción del Corán. Es asimismo el único

34 No obstante, sí que incluye la glosa final sobre la hégira, lo que hace pensar que el modelo podría tener alguna de las glosas originales, que no habrían sido copiadas: Albigera (sic) arabice dicitur tempus sublimationis prophete uel regis. Et secundum hoc Machometus cepit regnare uel pocius extolli anno Domini VI VI. Tot namque remanent, facta diminucione 537,1143 .

35 Ed. Bündgens et al., "Die Errores legis Mahumeti”, pp. 215-248. 
que ofrece, a continuación de esta traducción, los Errores legis Mahumeti redactados por Juan de Segobia.

Si la presencia en el códice de los Errores es ya un indicio claro de la relación entre manuscrito y letrado, la hipótesis de que la procedencia directa o indirecta del códice parisino está en el scriptorium del priorato de Aiton, donde Juan de Segobia pasó sus últimos años y elaboró su propia recensión trilingüe del Corán, se confirma a la luz de la descripción que este dio de los códices del Corán latino por él donados en octubre de 1457 a la Universidad de Salamanca y al convento mercedario de Valladolid. He aquí estas noticias ${ }^{36}$.

Donatio bibliothecae Uniuersitatis

[n. 25] Alcuranus secundum primam translacionem. Prime membrane ultima linea sic dicit: quos poterat publice occidendo, terrorem sui auxit. Et sepe congressionibus factus. Ultime uero membrane, de titulis psalmorum, <prima linea $>$ sic dicit: de familiari. $X X X V^{37}$.

[n. 71] Item Alcoranus, lex Mahometi, secundum antiquam translationem, eiusque Errores summarie excerpti. Prime membrane ultima linea sic dicit: Ante annos $V^{e}$ fere et quinquaginta, arabs nacione, uilis genere. Ultime membrane prima linea sic dicit: Alcurani Deus poneret pro diuino timore funditus dissolueretur et quod licet.

Donatio conuentui sanctae Marie de Mercede Vallisoleti

[n. 107] Dono rursus condicionibus predictis librarie conuentus sancte Marie de Mercede oppidi prefati Vallisoletani librum Alcurani, quem sarraceni pro diuina uenerantur lege; et continet in principio epistulas duas Petri abbatis Clunyacensis, mandato cuius facta est in regno Castelle translacio prefati libri de arabico in latinum anno a natiuitate domini nostri Iesu Christi $\mathrm{M}^{\circ} \mathrm{CXLIIII}^{\circ}$ : illarum uero epistolarum prima explicat in summa sarracenorum heresim; secunda est ad sanctum Bernardum Clarauallis abbatem, ut contra ipsam scriberet sectam. Sunt uero alie due epistole Roberti translatoris. Item in fine libri continentur tituli ac

36 Ed. Hernández, Biblioteca de Juan de Segovia, pp. 90, 101, 112-113.

37 Por la referencia a la primera página, se deduce que el manuscrito estaba encabezado por la Summa totius heresis. Lo mismo puede decirse del segundo de los ejemplares descritos. numerus psalmorum, prout sunt in arabico. Errores quoque extracti iuxta dictam translacionem, propterea in multis deficientem, causam dantem ut $2^{\text {a }}$ fieret translacio expensis magnis laboreque horum donatoris librorum. Liber hic Alcurani in pergameno scriptus est, et prime membrane ultima linea sic dicit: Attentauit. Et quia barbaros barbarus et inter ydolatras ipse ydolatra. Postreme uero membrane prima linea dicit: -rant de predestinatis igni, sed iudeis christianisque predicans nullam legem bonam esse, niso tantum creato-.

Es obvio que la composición del manuscrito de la BNF es muy semejante a la de los ejemplares descritos en $\& 71$ y \&107. Ambos contienen el Corán seguido por los Errores. Además, la descripción del códice cedido al convento de Valladolid precisa que el Corán viene precedido, como el de la BNF, por las dos epístolas de Pedro el Venerable y los dos prefacios de Robert de Ketton. Ahora bien, no es posible identificar ninguno de estos manuscritos con el parisino, pues ni coinciden los íncipit y éxplicit del primer y último folio $^{38}$, ni en el ejemplar de la BNF aparecen los tituli psalmorum (esto es, las denominaciones árabes tradicionales de cada sura) a las que se alude en el final de la descripción del ms. 107 en el documento de Donación. Téngase en cuenta, además, que el material del códice donado era pergamino, no papel.

En consecuencia, parece que nos hallamos ante una nueva copia del Alchoran de Robert de Ketton poseído por Juan de Segobia, hasta ahora no identificada como tal. Ahora bien, cabe preguntarse si se trata de una copia producida en el propio scriptorium de Aiton en vida de Juan de Segobia o si fue ejecutada en fecha posterior en algún otro lugar.

La respuesta a esta cuestión podría obtenerse a partir de la consideración de la historia del manuscrito mismo. Por una parte, este no puede ser anterior a los años 1453-1455, fecha de redacción de los Errores $^{39}$. Seguramente el ejemplar

38 En la última línea del folio $4 \mathrm{r}$ del ms. parisino se lee: -gem suam conuertet christianos autem qui iam a. En la primera del folio 220v: auctorem qui homicida erat ab initio et in ueritate.

39 En varios lugares Juan de Segobia declara que desde varios años atrás se había ocupado de efectuar excerpta del texto coránico con el fin de compilar una lista de sus principales errores. Véase, por ejemplo: Etenim cum uestra concessione librum ipsum Alchoran habuerim anno $X X X$ $V I I^{\circ}$ sepeque in eo legeram et errores excerperam (epístola a Nicolás de Cusa: ms. BAV Vat. Lat. 2923, f. 6v). Cum iam ab annis plurimis ex dicto libro adnotatos excerpsis- 
mismo o su modelo fue elaborado durante los últimos años de vida de Juan de Segobia, cuando este más se esforzó por culminar y difundir sus trabajos islamológicos, en un rango de fechas coincidente con las redacciones del prefacio a la traducción del Corán (1456), de la carta de donación a la Universidad de Salamanca y al convento mercedario de Valladolid (9/10/1457) y de la confección del códice BAV lat. vat. 2923 destinado a Eneas Silvio Piccolomini ${ }^{40}$ (mayo 1458).

$\mathrm{Su}$ trayectoria posterior puede reconstruirse parcialmente a partir de las siguientes consideraciones. El códice ingresó en la Bibliothèque Royale de Paris en 1685, como parte de una legación de Ulrich Obrecht (1646-1701). Este había sido profesor de Derecho en la Universidad de Estrasburgo hasta 1672, senador y pretor regio para Alsacia desde $1685^{41}$. Previamente había pertenecido a un tal Stephanus de Comitiis, personaje desconocido, cuya firma y ex libris, como ya se ha dicho, aparecen consignados en los folios 3v. y $225 \mathrm{v}$.

Pero el indicio de mayor interés para conocer la situación del manuscrito en la primera etapa de su trayectoria es el hecho de que presente un añadido muy significativo: la invectiva contra el Corán de Martin le Franc, un poema en dieciséis dísticos elegíacos copiado en el folio 3v. por una mano diferente de la que transcribió el resto de los textos. Se trata del único ejemplar conocido de esta composición, que transcribimos en apéndice, y también la única muestra conocida de la poesía latina de Martin.

En la actualidad Martin le Franc es recordado principalmente por su condición de autor del poema Le Champion des dames (1440-1442) y del prosímetro L'Estrif de Fortune et Vertu (1447-1448). Pero es su carrera eclesiástica la que ofrece más interés para el asunto que nos ocupa. Desde muy joven estuvo ligado a la cancillería del duque Amadeo VIII de Saboya y, cuando en 1439 éste fue nombrado papa, tomando el nombre de Félix V, ejerció el cargo de secretario apostólico hasta la abdicación de aquel

sem errores (De gladio diuini spiritus, praefatio, ed. Roth, Johannes de Segovia, p. 20, 11. 224-225). Pero la versión final de esta summa debe datar de 1455, según el siguiente pasaje de la epístola a Jean Germain de 18/2/1455: Destino preterea articulos erroneos in lege contentos Mahumeti per me anno isto excerptos (ms. BAV Vat. Lat. 2923, f. 48v).

40 Sobre este manuscrito, véase el importante estudio de Scotto, "Juan de Segovia's Last Manuscript", pp. 61-81.

${ }^{41}$ Sobre Ulrich Obrecht véase: Omont, Anciens inventaires et catalogues, p. 496. en 1449. Al servicio de Félix, Martin se incorporó al concilio de Basilea en julio de 1440, y allí tuvo ocasión de conocer a otros ilustres participantes, como Nicolás de Cusa y Eneas Silvio Piccolomini. De hecho, Martin es uno de los personajes de los diálogos del Libellus dialogorum de auctoritate concilii generalis ac de gestis Basiliensium et Eugenii papae contradictione, compuesto por Eneas Silvio Piccolomini en noviembre de $1440^{42}$. El resto de su carrera puede resumirse así: preboste de Lausanne desde 1443 y canónigo de Ginebra desde 1447, tras la abdicación de Félix V en 1449 y su muerte en 1451, permaneció ligado a la cancillería del ducado de Saboya, ahora regentada por Ludovico I. Finalmente, desde 1459 desempeñó el cargo de administrador de la abadía piamontesa de Novalaise, en la frontera entre Italia, Francia y Suiza. Falleció en Ginebra en $1461^{43}$.

Aunque no existen evidencias concretas, es muy probable que Martin mantuviese algún contacto con Juan de Segobia, dado que tenían amistades comunes y ambos estaban al servicio de los intereses de Félix V. Cabría, pues, suponer que el manuscrito en cuestión fuese expedido desde Aiton a la cancillería de Saboya durante los últimos años de vida de Juan de Segobia. Ahora bien, si así fuese, se esperaría que en el propio códice, o en algún punto del epistolario de Juan, hubiese alguna referencia expresa a este legado, pero no he hallado ningún indicio al respecto. Por otra parte, la consideración de la marca de agua del papel empleado en el códice, una cabeza de buey rematada por un trazo en forma de estrella (Briquet, Les filigranes, $\mathrm{n}^{\circ}$ 15049) es ligeramente diferente a la característica de otros códices provenientes con seguridad del scriptorium de Aiton, como el BAV Vat. Lat. 2923, que presenta una cabeza de buey sobre una cruz latina ${ }^{44}$.

Una hipótesis alternativa es que nuestro manuscrito fuese una copia ejecutada fuera ya del scriptorium de Aiton, tal vez por encargo del propio Martin o por otro miembro de la cancillería del ducado. Encajaría con esta suposición el hecho de que una parte al menos de los manuscritos legados por Juan de Segobia a la Universidad

42 Ed. Kollar, Analecta monumentorum omnis aevi Vindobonensis, II. Wien, 1762, col. 685-790, [en línea], disponible en: <http://digital.ub.uni-duesseldorf.de/ihd/content/ titleinfo/2089890>, [consultado el 7/7/2020].

43 Sobre Martin le Franc, remito al estudio de Jung, "Situation de Martin le Franc", pp. 13-30.

44 Scotto, "Juan de Segovia's Last Manuscript", p. 63. 
de Salamanca y a los mercedarios de Valladolid pasaron, en su viaje a Castilla, por Ginebra. Se conserva una nota de la cancillería papal, de 10 de febrero de 1459, en la que consta el pago de catorce florines a un tal Fernando de Viroes, nepos de Juan de Segobia, por el transporte a Ginebra de ciertos libros por encargo expreso del papa Pío $\mathrm{II}^{45}$. Tres días antes, esto es, el 7 de febrero de ese mismo año, el propio pontífice había promulgado una bula dirigida a la Universidad de Salamanca, por la que reclamaba para sí algunos de estos ejemplares. Como señala $\mathrm{Scotto}^{46}$, es posible que los códices solicitados (o copias de los mismos) le fuesen entregados al papa en Perugia en febrero de 1459 por los embajadores del duque de Saboya Ludovico I y pasasen a engrosar su propia biblioteca en Siena. Pero lo cierto es que carecemos de datos seguros sobre la suerte final que corrieron muchos de los ejemplares del legado de Juan de Segobia, que hoy en día se han perdido o no se encuentran localizados.

En conclusión, el ms. BNF lat. 3669 pudo haber sido copiado en Ginebra en los años inmediatamente posteriores a la muerte de Juan de Segobia, tal vez a inicios de 1459 , a partir del ejemplar donado al convento mercedario de Valladolid. Cabe suponer que, en vista del interés que mostraba el Pontífice Pío II por los libros destinados a España, el propio Martin le Franc o algún otro miembro de la cancillería del ducado de Saboya decidiese encargar una copia de, por lo menos, este códice en particular. Sea cual fuese su suerte ulterior, dos siglos después el ejemplar se encontraba todavía en una zona próxima al ducado de Saboya: en la ciudad de Estrasburgo, a solo unos trescientos kilómetros de Ginebra.

\section{EI manuscrito BNF lat. 3669: exponente de la recensión de Juan de Segobia del Corán latino}

La siguiente hipótesis que voy a defender es la de considerar el ms. BNF lat. 3669 como exponente del ejercicio de revisión que Juan de Segobia hizo de la versión latina del Corán de Robert de Ketton mediante el cotejo de los manuscritos que declara haber poseído. En la práctica, me limitaré a presentar la redacción de $P^{7}$ como resultado de la introducción de una serie de variantes características de la familia $\beta$, procedentes de la copia del Corán traído de Constantinopla por Johannes de Ragusio, en un texto base procedente de un códice de la familia $\alpha$, concretamente del grupo $M^{i} B P^{4}$, y muy próximo al ms. BNF lat. $3393\left(P^{4}\right)$.

Pondré a continuación algunos ejemplos de estas tres series de variantes.

\section{Primera serie}

$\begin{array}{ll}\boldsymbol{P}^{7} \boldsymbol{\beta} \boldsymbol{B i b l} . & \boldsymbol{A} \boldsymbol{\alpha} \\ \text { Disputationem } & \text { Contentionem (s. 4:23) } \\ \text { Cibumque tuum } & \text { Cibumque tuum et uinum (s. 4:32) } \\ \text { Connexionem } & \text { Conexum (s. 4:33) } \\ \text { Alioquin } & \text { Alloquium (4:46) } \\ \text { Ostendendo } & \text { Ostentando (4:48) } \\ \text { Vero contraria } & \text { Vero quasi contraria (5:7) } \\ \text { Pauperes eleuans } & \text { Pauperes subleuans (5:53) }\end{array}$

45 Roma, Archivio di Stato, Fondo Camerale I, 834, f. 78r: "[G]ilifortes etc. mandamus quatenus de pecuniis dicte Camere solvatis honorabili viro Fernando de Viroes nepoti quondam domini Johannis de Segobia florenos auri de Camera quatuordecim pro suis expensis in eundo Gebennas ad portandum certos libros de mandato et pro Sanctissimo domino nostro papa quos in vestris computis admittemus. / Datum Perusii die x. mensis februarii anno Domini meccclviiii etc. ut supra [...]". Cito por la edición de Scotto, "Juan de Segovia's Last Manuscript", p. 71, n. 32.

46 Scotto, "Juan de Segovia's Last Manuscript", pp. 6970. 


\section{Omissum}

Teste se extitissent

Ad deorum secta

Purgamentum

Sustentamentum

Hec et alia facere

Dilectores / Dilectiores

Vtrum te uerum dixisse

Omnipotentem

Deus sapiens

Suos actus

Prae ceteris

Super omnes extulit

Meis preceptis contradicentes

Sequentes ratione uique doctorem

Altiscens

Miraculum

Remue gestabilem

Mandatum

Bene formosum

Quamdiu uiueret Ascemeli

Saluamus singulariter credentes

Duo paria induceret

Non pollutis

Sicque credentes, Moysen

$\mathrm{Nec}$ ego reiicere possum

Hemen autem illi artifici Pharao

Ad tuam haram fecimus

Laborem et damnum et malum

Deus solum illos

A Deo cuncta uidente et audiente

Qui nostris preceptis contradixistis

Quadraginta pauperes pascat

Cunctis hominibus

Aggredi uel expugnare

Mandatum a me profertur

Vindicareue queso / quaero

Deinceps uias suas patefecit

Similiterque inter se
Cur uera falsis ammiscetis? (5:154)

Testes extitissent $(5: 190-1)$

Ad eorum sectam (6:20-21)

Purgamen (6:108)

Sustentamen (7:5)

Hec et illa facere (10:91)

Dilecturos (12:182)

Vt tum te uerum dixisse (13:86)

Potentem (15:4)

Sapiens (15:117)

Omnes suos actus (16:128)

Preteritis (17:74-75)

Super omnes gentes extulit (17:269-270)

Nostris preceptis contradicentes (17:378)

Sequentes recte uie doctorem (17:387)

Asciscens (19:97)

Mirandum (21:154)

Rem uegetabilem (25:21)

Mendacium (26:110)

Lene, formosum (27:46)

Quamdiu uiueret (30:132-133)

Saluamus semper credentes (31:124-5)

Duo paria includeret (33:31)

Impollutis (34:57-58)

Sicque Moysen (36:66)

Nec ego credentes reicere possum (36:97-98)

Hemen autem (38:85)

Ad terram haran fecimus (38:120-121)

Laborem et malum (48:55)

Deus saltim illos (50:89)

a Deo cuncta uidente (54:3)

Qui nostris contradixistis (60:27)

Sexaginta pauperes pascat (s. 68:11-12)

Ceteris hominibus $(68: 45)$

Aggredi uel impugnare (69:35)

Mandatum a me diuinitus proferret (s. 79:33)

Vindicareue queo (82:27)

Deinceps uias patefecit (s. 90:11-12)

Similiterque marium inter se (s. 91:4)

\section{Segunda serie}

\section{$\boldsymbol{P}^{7} \boldsymbol{P}^{4} \boldsymbol{B} \boldsymbol{M}^{i}$}

ad alteram

pactum huiusmodi confirmastis?

spem bonis polliceatur

qualiter populus Israel

qualiter alter alterum fecerit

et thronum Dei ascendit

Deum non timendo, narrant

et ibi portantes aquam

pretermissorum mercedem

in umbram dicendo dixit

malique per succesorem

quin malam proficiscar

quos adorastis in Dei loco

gratificamus

nec credentes

\section{Caet.}

ad terram $(2: 60)$

pactum huiusmodi firmastis? $(2: 144)$

spem bonam bonis polliceatur $(2: 178)$

qualiter populus filiorum Israel $(3: 116)$

qualiter alter alterum interfecerit (12:96-97)

et thronum ascendit $(17: 116)$

Deum non timendo, uariant $(18: 114)$

et ibi potantes aquam (19:45-46)

premissorum mercedem (19:79-80)

in umbram discedendo dixit (38:52)

malique persuasorem $(45: 15)$

quin malam uiam proficiscar (45:28)

quos adorastis mei loco $(46: 18)$

te glorificamus $(53: 16)$

nec credentes nec rectam uiam uidentes (s. 56:20) 
Die uero generalis creduli ut se iudicaret iniungens eructuando fiat in die prefinita coadunatos ueritatique porte consentire nemini proderit sua gens sua proles nuncium ex semetipsis excreauit quis fuit finis accessorium hortorum et omnium donum minime parabat se rediturum hanc uiam plus alia diligitis egressus retrorsum efficitur quod uobis euidenter imperabitur
Die uero generalis edicti (s. 64:7-8) ut se uindicaret iniungens (s. 64:13-14) trutinando fiat (65:6) in die prefinita coadunandos (s. 66:24-25) ueritatique posite consentire (s. 67:37) nemini proderit sua gens seu proles (s. 70:11-12) nuncium ex semetipsis excitauit (s. 72:4-5) quis fuit finis antecessorum (77:25) hortorum et amnium donum (s. 81:13) minime sperabat se rediturum (s. 94:9-10) hanc uitam plus alia diligitis (s. 97:11) gressus retrorsum efficitur (101:7) quod uobis euidenter improperabitur (s. 112:4)

\section{Tercera serie}

\section{$\boldsymbol{P}^{7} \boldsymbol{P}^{4}$}

Hostes atque pugnatores ut prosint pro parentibus et omnia liberat aequanimiter archent/arcent iudicium postulant liber hic inde gerenda trahit in illis

oberrare

sicque sunt facti quadraginta dies ad rerum alterius comparationem bonum nullus auferre poterit nunc supplici uoce precans hospitibus... ad Deum ingressis Dei miracula dinumerare ipsi sibi soli mala fecere Deo iubente, pressit Licet plurimum sit uotum uitamque rectam minus subest prolisque primorum parentum uestrorum manus in sinu tuo porrecta sperans se Deo commendandum redibunt singula die speciosa subuenissent exercitus bene michi gentique Dauid sunt quales cecus et uidens uineas atque palmem fontesque si uerax est uelle suum minime perficiunt ego imperans mari cognoscit minus est sunt precepta consentimur super suos uult genteque mala liberatis sufflans

\section{Caet.}

hostes atque pugnaces (2b:114)

ut prosint parentibus $(3: 30)$

et omnia librat aequanimiter $(4: 111)$

a Theut iudicium postulant (9:95)

liber hic inde gerenda tradit $(10: 105)$

uillis (17:5)

aberrare (17:77)

sicque sunt facti quadraginta (17:274)

ad rerum alius comparationem (19:96)

bonum munus nullus auferre poterit (20:220-21)

nunc supplici uoto precans (21:99-100)

hospitibus... ad eum ingressis (25:52)

Dei mirabilia dinumerare (25:26)

ipsi sibi mala fecere $(26: 56)$

Deo iubente, presserunt (26:209-10)

Licet plurium sit uotum $(27: 35)$

uiamque rectam (28:16)

minus substantie prolisque (28:87-88)

primorum patrum uestrorum $(36: 27)$

manus in sinu tuo posita (37:18-19)

sperans se Deo couniendum (39:6-7)

redibunt singula die spaciosa $(42: 11)$

superuenissent exercitus $(43: 29)$

unde michi gentique Dauid (44:28-29)

sunt equales cecus et uidens (45:41-42)

uineas atque palmeta fontesque (46:37)

si uerax es (46:56)

uelle suum omne perficiunt (49:140-41)

ego imperans Mizere (53:62-63)

agnoscit (53:105)

nil est (57:64)

super precepta $(68: 24-25)$

consentiunt (68:46)

super quos uult $(69: 14)$

genteque mala liberans $(76: 32)$

sufflauos $(87: 18)$ 
Otros indicios ilustrativos del modo en que el copista de $P^{7}$ habría cotejado sus dos modelos aparecen en aquellos lugares don- de se consignan sucesivamente dos variantes procedentes de manuscritos de las familias $\alpha$ y $\beta$ :

\author{
4:65: dando $(A \alpha)$ \\ 5:108: depositioni $(A \alpha)$ \\ 9:120: misericordem $(A \alpha)$ \\ 12:46: igni gehenne $(A \alpha)$ \\ 28:10: qui cunctis $(\alpha)$ \\ 46:11: nos, mortuos $(A \alpha)$ \\ 76:34: insufflauimus ei $(\alpha)$ \\ 121: 3: quin: $(A \alpha \beta)$
}

\author{
quando $(\beta)$ \\ dispositioni ( $\beta$ Bibl.) \\ minime $(\beta$ Bibl. $)$ \\ ipsi gehenne ( $\beta$ Bibl.) \\ qui cunctas $(A \beta B i b l$. $)$ \\ uos, mortuos $(\beta)$ \\ insufflauimus illi $(A \beta)$ \\ quando: (Bibl.)
}

\author{
quando dando $\left(P^{7}\right)$ \\ depotacioni disposicioni $\left(P^{7}\right)$ \\ minime misericordem $\left(P^{7}\right)$ \\ ipsi igne gehenne $\left(P^{7}\right)$ \\ cunctis, qui cunctas $\left(P^{7}\right)$ \\ nos mortuos uos mortuos $\left(P^{7}\right)$ \\ insufflauimus illi ei $\left(P^{7}\right)$ \\ quando quin: $\left(P^{7}\right)$
}

Por último, también se pueden detectar variantes coincidentes del manuscrito $P^{7}$ con el texto de los Errores legis Mahumeti:

88:20: pupillis ( $P^{7}$ Errores, 1. 9)

27:158-9: causa uenirent ( $P^{7} W K$ Bibl. Errores, 1. 318) papillis (caet.)

conuenirent (caet.)

Y también con el De mittendo gladio.

65:6: eructuando fiat ( $M^{i} B P^{4} P^{7}$ De mittendo 11:75)

trutinando fiat (caet.)

\section{Conclusiones}

A partir del año 1437, Juan de Segobia comenzó a estudiar el Alchoran de Robert de Ketton a partir de dos ejemplares de muy baja calidad: el hallado en una biblioteca alemana y el que recibió en préstamo de Nicolás de Cusa. Tras descubrir el códice traído por Johannes de Ragusio a Basilea, corrigió las copias que poseía o más bien efectuó una nueva recensión del texto, la que ofrece el manuscrito $P^{7}$. De forma paralela, Nicolás de Cusa trabajó primero sobre el manuscrito $B$, de características semejantes a $M^{i}$ y $P^{4}$, y años después prosiguió sus estudios coránicos tomando como fuente un ejemplar muy superior, el BAV Vat. Lat. 4071, derivado del códice de Johannes de Ragusio depositado en el convento dominico de Basilea.

El hecho de que Juan de Segobia reconociese y difundiese en sus escritos la calidad del manuscrito ragusino seguramente contribuyó de forma importante a que en la segunda mitad del siglo XV y primera del XVI diferentes per- sonajes encargasen nuevas copias, lo que daría lugar a la familia $\beta$.

La propia selección de los textos presentes en $P^{7}$, que excluye la Chronica mendosa, el Liber generationis Mahumet, la Doctrina Mahumet, la Epistola Sarraceni y el Rescriptum Christiani, es coherente con el interés de Juan de Segobia por efectuar una aproximación al Corán no condicionada por la tradición musulmana posterior ni tampoco por la literatura cristiana de controversia.

Subsisten, por último, varias dudas, que habrán de resolverse en futuras investigaciones: el manuscrito $P^{4}$ ¿perteneció a Juan de Segobia? ¿es más bien un derivado de uno de sus libros? ¿o no guarda ninguna relación con el letrado? Tampoco está clara la procedencia del manuscrito copiado por Nicolás de Cusa y Francesco Pizolpasso: ¿un códice custodiado en una biblioteca de Basilea o traído a Basilea por algún delegado conciliar? E igualmente incierta es la biblioteca alemana que custodiaba el códice encadenado del que se procuró una copia Juan de Segobia. 


\section{Apéndice I}

El texto de los Errores legis Mahumeti en Paris BNF lat. 3669

La edición de Bündgens et alii se basa en los manuscritos Città del Vaticano, BAV, ms. Vat. Lat. 2923, ff. 157v-164 r (s. XV), y Sevi1la, Biblioteca Colombina, ms. 7-6-14, ff. 130133 (s. XV). Los editores, pues, no han tenido en cuenta el ms. BNF lat. 3669. Anoto, a continuación, las variantes que presenta éste con respecto al texto editado. Algunas de estas ilustran el continuo proceso de revisión que efectuó Juan de Segobia sobre el texto. Particularmente interesantes, a este respecto, me parecen las variantes pupillis / papillis, referidas a un pasaje de la sura 87. Papillis es la lectura que dan todos los manuscritos, a excepción precisamente del códice $P^{7}$, que presenta pupillis. También es significativa la variación parate / arate, en referencia al conocido pasaje de la sura 3: Mulieres uobis subiectas penitus pro modo uestro, ubicunque uolueritis, perarate (ms. Arsenal, f. 31va). La lectura original solo se ha mantenido en los manuscritos $O^{1} O^{2} P^{2} P^{6}$ $P^{3} S^{p}$. El resto (incluido el códice $P^{\urcorner}$) da parate, pero curiosamente uno de los manuscritos de la familia $\beta$, el de Dresden, Sachsische Landesbibliothek, Mscr. Dresd A. 120b (D) presenta la anotación supralineal: uel arate ar. $^{47}$.

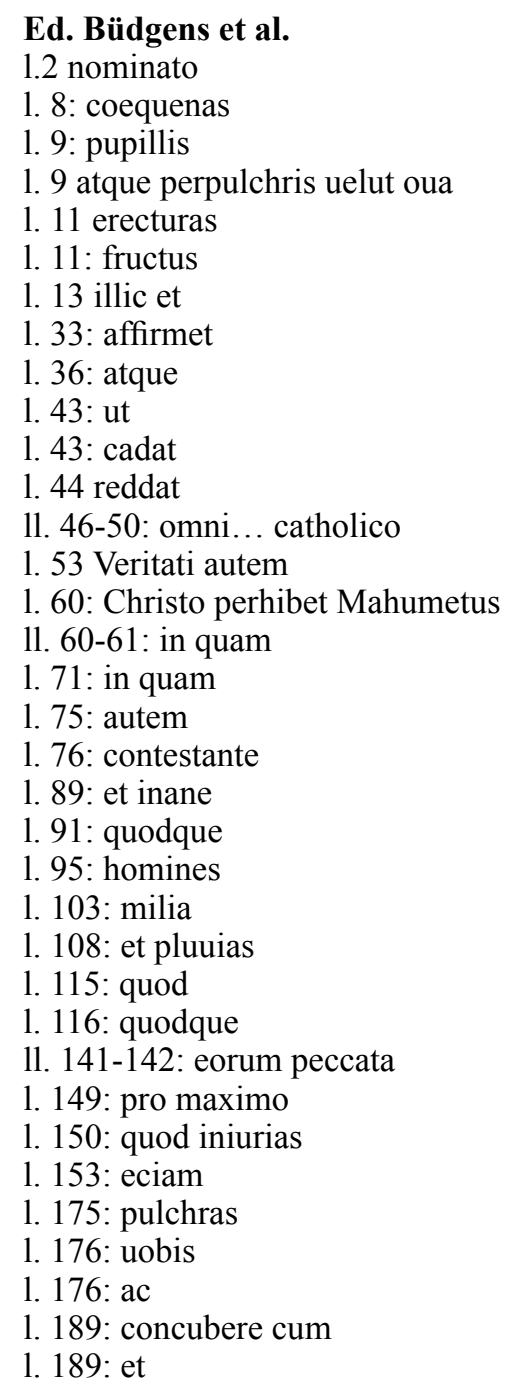

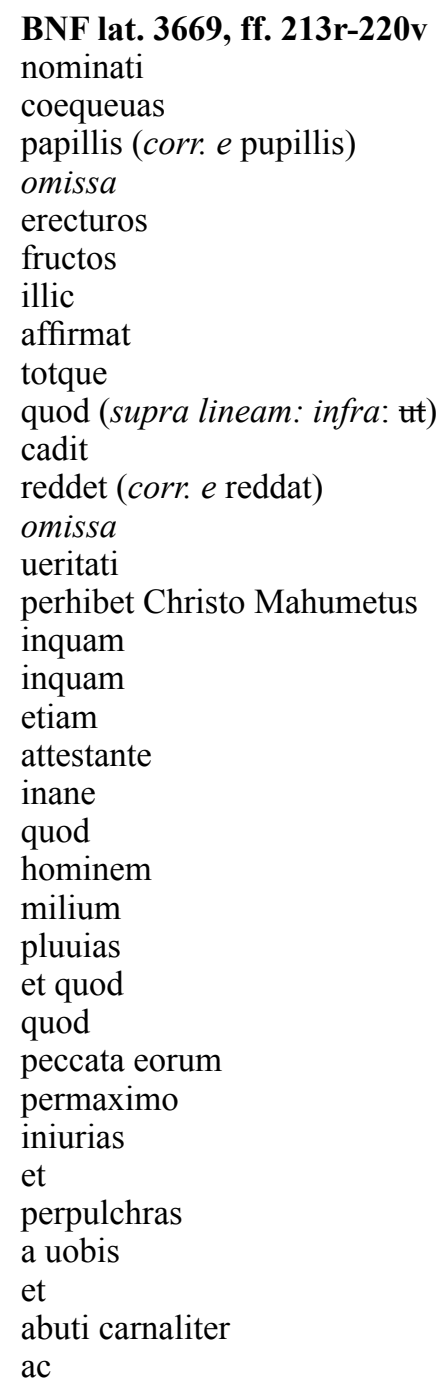

47 Arate es también la lectura que se registra en el pasaje correspondiente de la Tabula copiada en este mismo manuscrito (capitulo sexto, f. xxxixr). 


$\begin{array}{ll}\text { 1. 201: parate } & \text { arate } \\ \text { 1. 206: uero } & \text { autem } \\ \text { 1.215: generalem igitur } & \text { generalemque } \\ \text { 1. } 269 \text { scilicet scripture } & \text { scripture } \\ \text { 1.272: postremi } & \text { extremi } \\ \text { 1. } 273: \text { forte satis } & \text { fore satis } \\ \text { 1. } 290: \text { nec } & \text { ne }(\text { corr. } \text { e nec }) \\ \text { 1. 293: O filii Israhel } & \text { O filii } \\ \text { 1. 294: de testamentis } & \text { de testamento } \\ \text { 1. 299: fuerint } & \text { fuerunt } \\ \text { 1. } 315: \text { leuis } & \text { lenis } \\ \text { 1. 324: operiens } & \text { operiens se (se supra lineam) } \\ \text { 1. } 330: \text { fuit } & \text { erat }\end{array}$

\section{Apéndice II}

El poema contra el Corán de Martin le Franc (Ms. Paris BNF lat. 3669, f. 3v)

In Alchoran Machometi Martinus prepositus Lausanensis

I, liber, in tenebras dense fumantis abissi

Nec pateas nostros amplius ante oculos!

Non sole es dignus baratri conceptus in antro,

Nam qui te genuit Belzebuth ipse fuit.

Belzebuth ille fuit uel si mendacior ipso est

Te genito notus, tu patre notus eo.

Fraus tua sub quedam ueri simulachra latenter

Serpit, sed paruo cognita iudicio.

Legi detrectas, sacra obruis, impia fingens.

Solum Abraham sequeris. Omnia Christus habet

Finem promittis ubi femina summa uoluptas.

Si nichil est melius, hec paradisus eat.

O mortis laqueus, spurcissima fossa malorum!

Pestiferi erroris congeris omne nephas.

Irrediturus abi, ardenti carbone notandus

Aut cum gente sua te Machometus edat!

¡Ve, libro, a las tinieblas del abismo de espesa humareda

Y no te muestres más ante nuestros ojos!

Concebido en la caverna del infierno, no eres digno del sol,

Pues quien te engendró fue el propio Belcebú.

Fue Belcebú, sí, o uno más mendaz aún que él,

Famoso por haberte engendrado, famoso tú por tal progenitor.

Tu impostura serpea a escondidas bajo cierta apariencia

De verdad, mas se la reconoce por su escaso juicio.

Rechazas la Ley, arruinas su carácter sagrado inventando impiedades.

Sigues solo a Abraham. Cristo lo ofrece todo.

Prometes un destino en que la mujer es el placer supremo.

Si no hay nada mejor, ¡a paseo ese paradiso!

¡O lazo mortal, la más sórdida fosa de males!

Reúnes todos los pecados de un pestilente extravío.

¡Vete para no volver, digno de ser marcado con un carbón ardiente

$\mathrm{O}$ que sea Mahoma con su pueblo quien te devore! 


\section{Bibliografía}

Bibliander, Theodor (ed.), Machumetis Saracenorum principis, eiusque successorum vitae, ac doctrina, ipseque Alcoran, Basilea, Johannes Opporin, 1543, vol. I, pp. 7-188; $2^{\text {a }}$ ed. Basilea, Johannes Opporin, 1550

Biechler, James, "Three Manuscripts on Islam from the Library of Nicholas of Cusa", Manuscripta, 27 (1983), pp. 91-100.

Bobzin, Hartmut, Der Koran im Zeitalter der Reformation. Studien zur Frühgeschichte der Arabistik und Islamkunde in Europa, Stuttgart, Steiner, 1995, Beiruter Texte und Studien, Bd. 42.

Briquet, Charles Moïse, Les filigranes: Dictionnaire historique des marques du papier des leur apparition vers 1282 jusqu'en 1600, Leipzig, Verlag Von Karl W. Heirsmann, 1923.

Bündgens, Anna et al., "Die Errores legis Mahumeti des Johannes von Segovia", Neulateinisches Jahrbuch, 15 (2013), pp. 215-248.

Burman, Thomas, Reading the Qur'ān in Latin Christendom, 1140-1560, Philadelphia, University of Pennsylvania, 2007.

Cabanelas, Darío, Juan de Segovia y el problema islámico. Granada, Universidad de Granada, 2007, (1 edición: Madrid, Universidad Complutense, 1952).

D’Alverny, Maria Thérèse, "Deux traductions latines du Coran au Moyen Âge", Archives d'Histoire Doctrinale et Littéraire du Moyen Âge, 16 (1948), pp. 69-131.

D’Alverny, Maria Thérèse, "Quelques manuscrits de la Collectio Toletana", en Gilles Constable y James Kritzeck (eds.), Petrus Venerabilis 1156-1956, Roma, Orbis Catholicus and Herder, 1956, Studia Anselmiana, 40, pp. 202-218.

Ferrari, Mirella, "Un bibliotecario milanese del Quattrocento: Francesco della Croce", Ricerche storiche sulla Chiesa Ambrosiana, vol. X, Milano (1981), pp. 175-270.

Hernández Montes, Benigno, Biblioteca de Juan de Segovia. Edición y comentario de su escritura de donación, Madrid, CSIC, Instituto Francisco Suárez, 1984.

Juan de Segobia, De gladio Divini Spiritus in corda mittendo Sarracenorum, Ulli Roth (ed. y trad.), Wiesbaden, Harrassowitz, 2012, Corpus Islamo-Christianum, Series Latina, 7.
Jung, Marc-René, "Situation de Martin le Franc", en Monique Ornato y Nicole Pons (eds.), Pratiques de la culture écrite en France au XVe siècle, Turnhout, Brepols, 1995, pp. 13-30.

Kritzeck, James, Peter the Venerable and Islam, New Jersey, Princeton University Press, 1964.

Langeloh, Jacob, Der Islam auf dem Konzil von Basel (1431-1449). Eine Studie mit Editionen und Übersetzungen unter besonderer Berücksichtigung des Johannes von Ragusa, Wiesbaden, Harrassowitz, 2019, Corpus Islamo-Christianum, Series Latina, 10.

Lappin, Anthony John, Alchoran Latinus. Vol. III. Editiones Theodori Bibliandri (1543 et 1550), Roma, Aracne editrice, 2011.

Martínez Gázquez, José, "El prólogo de Juan de Segobia al Corán (Qur'ān) trilingüe (1456)", Mittellateinisches Jahrbuch, 38, 2 (2003), pp. 389-410.

Martínez Gázquez, José, “A New Set of Glosses to the Latin Qur'ān Made by Nicholas of Cusa (ms Vat. Lat. 4071)", Medieval Encounters, 21, 2-3 (2015), pp. 295-309.

Nicolás de Cusa, Cribratio Alkorani: Examen del Corán, Víctor Sanz Santacruz (ed. y trad.), Pamplona, EUNSA, 2013.

Omont, Henri, Anciens inventaires et catalogues de la Bibliothèque Nationale, vol. IV, París, E. Leroux, 1913.

Roth, Ulli, "Juan of Segovia's Translation of the Qur'ān”, Al-Qanțara, 35, 2 (2014), pp. 555-578.

Roth, Ulli and Glei, Reinhold, "Die Spuren der lateinischen Koranübersetzung des Juan de Segovia - alte Probleme und ein neuer Fund", Neulateinisches Jahrbuch, 11 (2009), pp. 109-154.

Roth, Ulli and Glei, Reinhold, "Eine weitere Spur der lateinischen Koranübersetzung des Juan de Segovia", Neulateinisches Jahrbuch, 13 (2011), pp. 221-228.

Scotto, Davide, “Juan de Segovia's Last Manuscript (ms. Vat. Lat. 2923). The Quest for Islam from the Aiton Library to Pope Pius II", en Rainer Berndt (ed.), Der Papst und das Buch im Spätmittelalter (1350-1500), Münster, Aschendorff Verlag, 2018, pp. 61-81.

Segesvary, Victor, L'Islam et la Réforme. Étude sur l'attitude des réformateurs zurichois envers l'Islam (15101550), Lausanne, Éditions l'Age d'Homme,1978. 